TITLE:

\title{
Flower-like surface modification of titania materials by lithium hydroxide solution.
}

\section{AUTHOR(S):}

Hasegawa, George; Kanamori, Kazuyoshi;

Sugawara, Yoshihiro; Ikuhara, Yuichi; Nakanishi, Kazuki

\section{CITATION:}

Hasegawa, George ... [et al]. Flower-like surface modification of titania materials by lithium hydroxide solution.. Journal of colloid and interface science 2012, 374(1): 291-296

\section{ISSUE DATE:}

2012-05-15

URL:

http://hdl.handle.net/2433/154923

\section{RIGHT:}

(c) 2012 Elsevier Inc.; この論文は出版社版でありません。引用の際には 出版社版をご確認ご利用ください。; This is not the published version. Please cite only the published version. 


\title{
Flower-like Surface Modification of Titania Materials by Lithium Hydroxide Solution
}

George Hasegawa, ${ }^{* a}$ Kazuyoshi Kanamori, ${ }^{\text {a }}$ Yoshihiro Sugawara, ${ }^{\text {b }}$ Yuichi Ikuhara, ${ }^{\text {b,c }}$ and Kazuki Nakanishi $^{\mathrm{a}}$

${ }^{a}$ Department of Chemistry, Graduate School of Science, Kyoto University, Kitashirakawa, Sakyo-ku, Kyoto 606-8502, Japan

b Japan Fine Ceramics Center, Mutsuno, Atsuta, Nagoya 456-8587, Japan

${ }^{c}$ Institute of Engineering Innovation, School of Engineering, The University of Tokyo, Yayoi, Bunkyo-ku, Tokyo 113-8656, Japan

*Corresponding author: George Hasegawa

TEL/FAX: +81757537 673

E-mail: h_george@kuchem.kyoto-u.ac.jp

\begin{abstract}
Surface modification of titania materials to give flower-like structures has been achieved simply by the treatment in lithium hydroxide aqueous solution under mild conditions. The flower-like structured materials were characterized by X-ray diffraction, thermogravimetric analysis,
\end{abstract}


and Raman scattering. The analyses indicate that the flower-like materials are composed of layered hydrous lithium titanate. It is suggested that the unique intercalation behavior of lithium ions into titania allows dissolution and re-precipitation of titania to form the flower-like structure. The obtained flower-like structure can be retained up to $700{ }^{\circ} \mathrm{C}$, while the crystal phase transforms into $\mathrm{Li}_{4} \mathrm{Ti}_{5} \mathrm{O}_{12}$.

Keywords; surface modification, flower-like structure, titania, crystalline layered titanate, lithium intercalation

\section{Introduction}

Since the first report of water-splitting on titania $\left(\mathrm{TiO}_{2}\right)$ electrodes under ultraviolet (UV) light irradiation by Fujishima and Honda in 1972 [1], titania has attracted a lot of attention and substantial efforts have been made on the development of the titania-based materials and devices [2-16]. Owing to its unique characteristics [2,3], titania is currently one of the most promising materials in various fields, such as photovoltaic cells [6,7], photocatalysis [8], and separation science $[9,10]$. For effective application to these purposes, the nanostructure design of titania is of great importance [10-16]. For example, porous structure is required for separation media [10], catalysts [14,15], and electrodes [16] to provide accessible high surface area.

Recently, we have fabricated hierarchically porous titania monoliths by the sol-gel 
technique accompanied by phase separation [17]. The control of the sol-gel reaction of titanium alkoxide can be achieved with the aid of chelating agent as well as appropriate electrolites [18], while the phase separation is induced by the addition of poly(ethylene glycol). The immobilization of the co-continuous structure, which is formed in the course of spinodal decomposition, by the sol-gel transition provides well-defined interconnected macropores. The mesopores with relatively narrow size distributions are formed as the interstices of anatase crystallites, which are formed after the removal of the chelating agent, in the macropore skeletons. This porous titania monolith shows good separation performance for organophosphates [19].

For functionalization and/or structural modification of materials surfaces, post-modification techniques are useful. In most cases, the post-modification changes only the chemical nature, such as functional groups, of the materials surfaces [20-23]. Some post-modification can change not only the chemical nature but also the surface structure of the materials, which provides even superior functionality of materials [24,25]. In the case of titania materials, the post-modification in structure is remarkably difficult due to the excellent stability [26,27]. For example, it is known that the hydrothermal treatment in a strong alkaline solution (>10 mol L $\mathrm{L}^{-1} \mathrm{NaOH}$ or $\left.\mathrm{KOH}\right)$ is necessary for the conversion of titania into layered titaniates with nanotube and nanofiber structures [28-30]. This method, however, changes the whole titania material into nanotubes or nanofibers due to the harsh condition and is not available for the surface modification while keeping the porous structure. 
In this research, the effects of the treatment in lithium hydroxide solution on the surface of the titania materials have been investigated. It was revealed for the first time that the treatment in lithium hydroxide aqueous solution under relatively mild conditions gives rise to the flower-like structure on the titania surface. This structural change is never observed when titania materials are treated in the other alkaline solution, such as ammonium hydroxide, sodium hydroxide, and potassium hydroxide [31,32], which indicates that the lithium ions have significant influence on this reaction. The flower-like structured material was characterized by X-ray diffraction, thermogravimetric analysis, and Raman scattering, and the formation mechanism of flower-like structure is discussed.

\section{Experimental}

\subsection{Chemicals}

Titanium (IV) $n$-propoxide $\left(\mathrm{Ti}(\mathrm{OPr})_{4}\right)$ and polyethylene glycol (PEG, $M_{\mathrm{v}}=10$ 000) were purchased from Sigma-Aldrich Co. (USA). Ethyl acetylacetonate (EtAcAc) and 1-propanol (PrOH) were purchased from Tokyo Chemical Industry Co., Ltd. (Japan). Ammonium nitrate $\left(\mathrm{NH}_{4} \mathrm{NO}_{3}\right)$ and lithium hydroxide monohydrate $\left(\mathrm{LiOH} \cdot \mathrm{H}_{2} \mathrm{O}\right)$ were obtained from Kishida Chemical Co., Ltd. (Japan). All reagents were used as received. Distilled water was used in all experiments. 
Porous titania monoliths were synthesized by the sol-gel method reported previously $[17,19]$. In a typical synthesis, $10 \mathrm{~mL}$ of $\mathrm{Ti}(\mathrm{OPr})_{4}, 7.0 \mathrm{~mL}$ of $\mathrm{PrOH}$ and $5.0 \mathrm{~mL}$ of EtAcAc were mixed in a glass tube. After obtaining a homogeneous yellow solution, $0.875 \mathrm{~g}$ of PEG was added followed by stirring at $60{ }^{\circ} \mathrm{C}$ and PEG was completely dissolved. Then, the solution was cooled to $40{ }^{\circ} \mathrm{C}$ and $2.0 \mathrm{~mL}$ of $1 \mathrm{~mol} \mathrm{~L}^{-1} \mathrm{NH}_{4} \mathrm{NO}_{3}$ aq. was added slowly with vigorous stirring. After mixing for 3 min, the obtained homogeneous solution was kept at $40^{\circ} \mathrm{C}$ for $24 \mathrm{~h}$. The obtained gels were sequentially immersed in the following solutions in a loosely closed container at $60{ }^{\circ} \mathrm{C}$ : ethanol $(\mathrm{EtOH}), \mathrm{EtOH} / \mathrm{H}_{2} \mathrm{O}=1 / 1$, and $\mathrm{H}_{2} \mathrm{O}$. Each immersion time was $24 \mathrm{~h}$. The chelating agent, EtAcAc, was removed by hydrolysis and decarbonation through this process, which also promotes the formation of anatase crystallites [17]. The obtained wet titania gels were dried at $60{ }^{\circ} \mathrm{C}$. The calcined titania monoliths were obtained by the calcination of the dried titania monoliths at different temperatures for $2 \mathrm{~h}$.

\subsection{Preparation of titania particles}

For preparing titania particles, $5.0 \mathrm{~mL}$ of $\mathrm{Ti}(\mathrm{OPr})_{4}$ and $10 \mathrm{~mL}$ of $\mathrm{PrOH}$ were mixed in a glass tube. Then, $1.0 \mathrm{~mL}$ of $\mathrm{H}_{2} \mathrm{O}$ was added slowly with vigorous stirring at $0{ }^{\circ} \mathrm{C}$. After the solution became opaque, the temperature was raised to room temperature and the solution was stirred for $1 \mathrm{~h}$. The resultant precipitants were washed with $\mathrm{H}_{2} \mathrm{O}$ followed by drying at $60{ }^{\circ} \mathrm{C}$.

\subsection{Surface modification}


For the treatment with $\mathrm{LiOH}$ aq., the wet titania gels (after washing with $\mathrm{H}_{2} \mathrm{O}$ ) were immersed in various concentrations of $\mathrm{LiOH}$ aq. at various temperatures in polypropylene containers. When the treatment temperature was more than $80^{\circ} \mathrm{C}$, the reaction was performed in an autoclave to inhibit the vaporization and the change of the concentration of $\mathrm{LiOH}$ aq. The resultant samples were washed with $\mathrm{H}_{2} \mathrm{O}$ at $60{ }^{\circ} \mathrm{C}$ for $3 \mathrm{~h}$ for five times in order to remove the excess $\mathrm{Li}$ ions. After evaporative drying at $60^{\circ} \mathrm{C}$, the dried surface-modified titania monoliths and particles were obtained. Some samples were subsequently calcined at various temperatures for $2 \mathrm{~h}$. The dried and calcined titania monoliths as well as the titania particles were also subjected to the same process.

\subsection{Characterization}

Observation of the microstructures of the fractured surfaces of the samples was conducted under scanning electron microscopy (SEM) (JSM-6060S, JEOL, Japan), field emission scanning electron microscopy (FE-SEM) (JSM-6700F, JEOL, Japan) and transmission electron microscopy (TEM) (JEM-2010DM, JEOL, Japan). The crystal structure was confirmed by powder X-ray diffraction (XRD) (RINT Ultima III, Rigaku Corp., Japan) using $\mathrm{Cu} \mathrm{K} \alpha(\lambda=0.154 \mathrm{~nm})$ as an incident beam. Nitrogen adsorption-desorption (BELSORP-mini II, Bel Japan Inc., Japan) was employed to characterize the meso- and micropores of the samples. Before nitrogen adsorption-desorption measurements, the samples were calcined at $200{ }^{\circ} \mathrm{C}$ for $2 \mathrm{~h}$ followed by being degassed under vacuum at $150{ }^{\circ} \mathrm{C}$ for more than $6 \mathrm{~h}$. Thermogravimetric (TG) analysis was 
performed by Thermo plus TG 8120 (Rigaku Corp., Japan) at a heating rate of $5{ }^{\circ} \mathrm{C} \min ^{-1}$. The titania particles were dried under vacuum to remove the adsorbed water before the measurement. In order to avoid the adsorption of water, the TG analysis was performed under argon atmosphere by supplying argon at a rate of $100 \mathrm{~mL} \mathrm{~min}^{-1}$. Raman spectrum of the sample was measured using a Jobin-Yvon T-6400 spectrometer (HORIBA, Ltd., Japan). The incident light used for the experiments was the $514.5 \mathrm{~nm}$ Ar line of the laser source (GLG3260, NEC Corp., Japan).

\section{Results and Discussion}

3.1 Effect of the concentration of $\mathrm{LiOH}$ aq. and the treatment temperature

Figure $1 \mathrm{a}$ and $\mathrm{b}$ show the change in structure of the titania monoliths by the treatment in 0.8 mol $\mathrm{L}^{-1} \mathrm{LiOH}$ aq. at $80{ }^{\circ} \mathrm{C}$ for $24 \mathrm{~h}$. The flower-like structure was formed with the platy crystallites on the titania surface with maintaining the macroporous structure. In addition, the crack-free monolithicity can also be retained as shown in the inset of Figure $1 \mathrm{~b}$. The SEM images of the samples with the different treatment times are shown in Figure S1. It is found that the platy crystallites become visible after the treatment for $5 \mathrm{~h}$. Comparing the samples treated for $6 \mathrm{~h}$ and $24 \mathrm{~h}$, number density of the platy crystallites is similar and the crystal size becomes larger with increasing the treatment time. When fixing the treatment temperature at $80{ }^{\circ} \mathrm{C}$, the flower-like structure was formed with the $\mathrm{LiOH}$-concentrations of $0.4 \sim 0.8 \mathrm{~mol} \mathrm{~L}^{-1}$ as shown in Figure $\mathrm{S} 2$. On the other hand, when fixing the concentration of $\mathrm{LiOH}$ aq. in $0.8 \mathrm{~mol} \mathrm{~L}^{-1}$, the flower-like structure was formed by the treatment at $60 \sim 80^{\circ} \mathrm{C}$ as shown in Figure S3. The results of the surface 
modification treated in various concentrations of $\mathrm{LiOH}$ aq. and at various temperatures are summarized in Figure $1 \mathrm{c}$, which indicates that the surface modification of titania materials is possible under defined conditions. As decreasing the concentration of LiOH aq., the flower-like structure was formed when the titania monoliths were treated at higher temperatures. The XRD patterns of the samples treated under various conditions are shown in Figure S4. When the treatment condition is weaker than $0.4 \mathrm{~mol} \mathrm{~L}{ }^{-1} \mathrm{LiOH}$ aq. at $60{ }^{\circ} \mathrm{C}$, no change in diffraction patterns was observed. On the other hand, when the treatment condition is stronger than $0.8 \mathrm{~mol} \mathrm{~L}^{-1} \mathrm{LiOH}$ aq. at $80{ }^{\circ} \mathrm{C}$, the $\mathrm{XRD}$ patterns exhibit an obvious change; most of anatase changes to $\mathrm{LiTiO}_{2}$ as reported previously [33]. It is also found that all XRD patterns of the samples with the flower-like structure include the same peaks of layered hydrous lithium titanate (LHLT) except for those of anatase, which will be discussed later. 


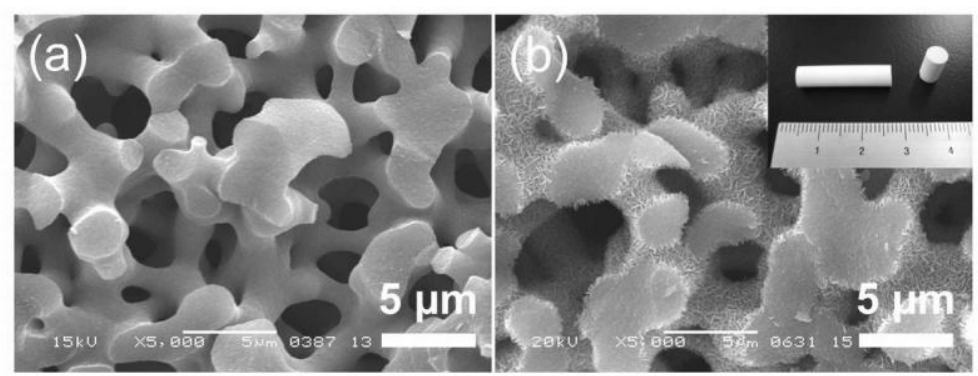

(c)

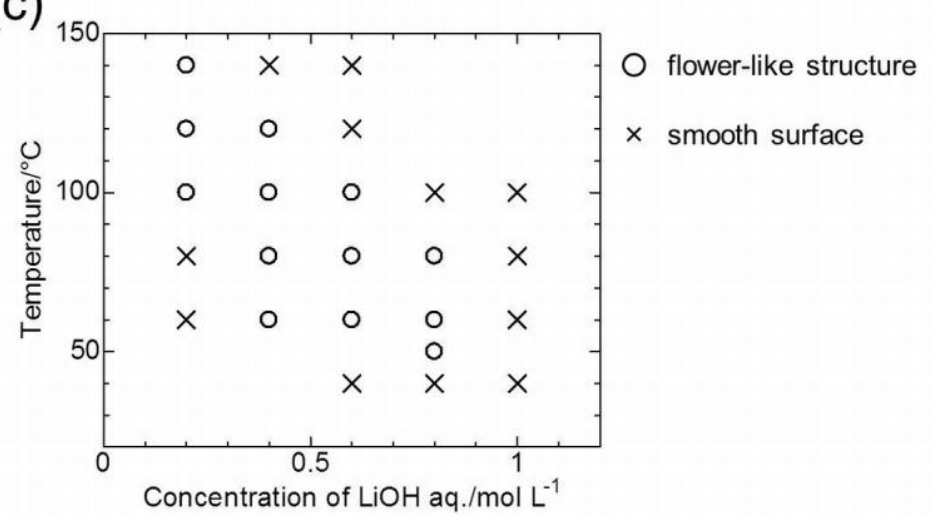

Figure 1 SEM images of the dried titania monolith (a) before and (b) after the treatment in 0.8 mol $\mathrm{L}^{-1} \mathrm{LiOH}$ aq. at $80{ }^{\circ} \mathrm{C}$ for $24 \mathrm{~h}$. The inset of (b) is the appearance of the surface-modified titania monolith. (c) Results of the treatment under various conditions for $24 \mathrm{~h}$. The platy crystallites were observed under SEM with the conditions designated as "flower-like structure" and no change was observed with the conditions as "smooth surface".

Figure $2 \mathrm{a}$ and $\mathrm{b}$ show the SEM images of the surface-modified samples which were subjected to the calcination at $700{ }^{\circ} \mathrm{C}$ and $800{ }^{\circ} \mathrm{C}$, respectively. It is found that the obtained flower-like structure was retained up to $700{ }^{\circ} \mathrm{C}$. The XRD patterns of the calcined surface-modified titania monoliths are shown in Figure $2 \mathrm{c}$. The peaks which are attributed to 
$\mathrm{LiTiO}_{2}$ are observed in the sample calcined at $200{ }^{\circ} \mathrm{C}$, while the peaks related to $\mathrm{Li}_{4} \mathrm{Ti}_{5} \mathrm{O}_{12}$ are observed in the samples calcined above $400^{\circ} \mathrm{C}$. It is notable that the peaks of anatase presumably from the skeletons of the macropores still remain even after the calcination at $700{ }^{\circ} \mathrm{C}$. The magnified image of the cross section of the skeleton also indicates that the platy materials appear only on the surface of the skeletons and that no change is observed in the inner part of the titania skeleton as shown in Figure 3 a. Figure $3 \mathrm{~b}$ and Table 1 show the micro- and mesopore characteristics of the titania monolith with and without the surface modification. The micro- and mesopore volume and the specific surface area slightly decreased by the surface modification due to the densification during the treatment and to the introduction of Li ions, which increases density of the titania monoliths. Most of the micro- and mesopores are deduced to derive from the original skeletons, not from the flower-like structure, which indicates that the pores of the anatase skeletons are still accessible even after the surface modification. For practical applications of this technique, it should be emphasized that the anatase phase, which shows excellent photocatalytic and bioseparation properties [2,3,6-10,19], can be retained as the major constituent in the material. For example, the resultant surface-modified macroporous titania monoliths may be utilized as the separation media $[10,19]$ with the additional function of ion-exchange ability. Besides, the surface modification on titania films (see Figure S5) for optical devices such as photocatalyst and photovoltaic cells, we can provide functionality such as anti-reflection [25] and water repellency [34], which can be derived from the flower-like structured coating, without losing the photoactivity of anatase. 

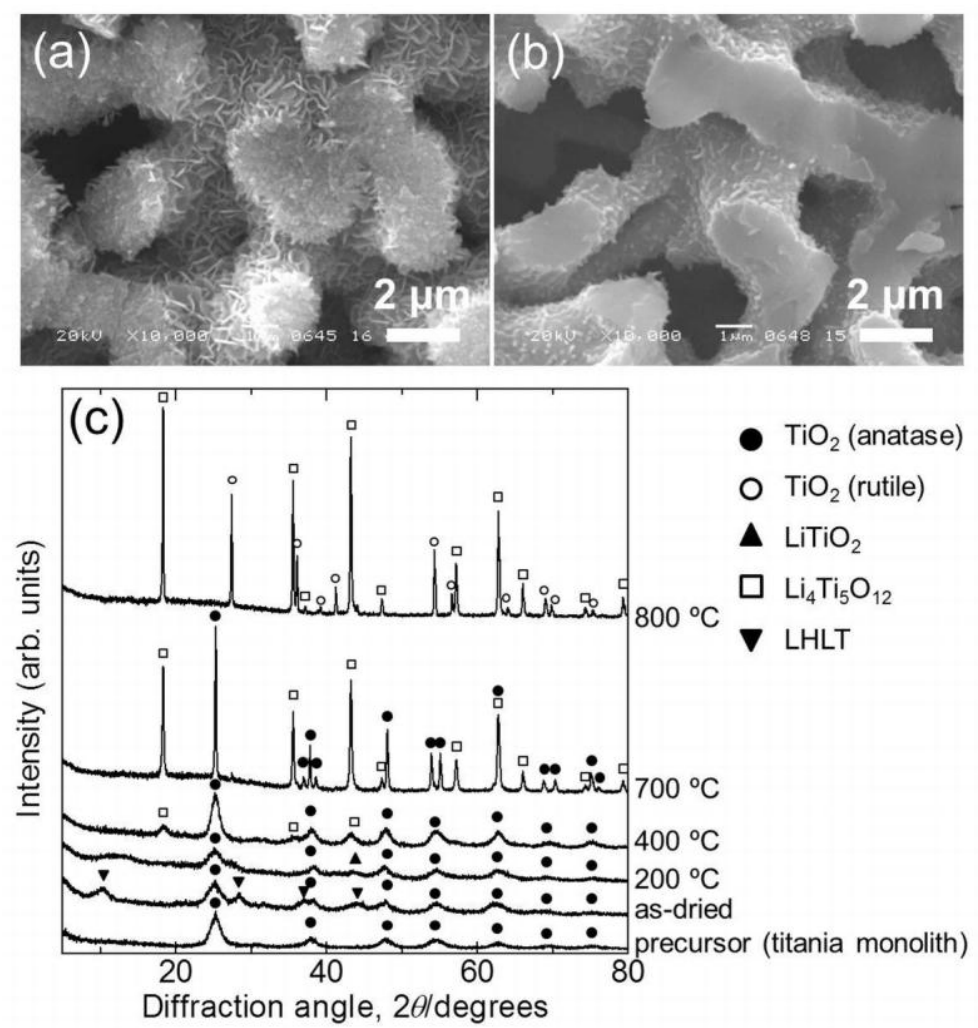

Figure 2 SEM images of the titania monoliths calcined at (a) $700{ }^{\circ} \mathrm{C}$ and (b) $800{ }^{\circ} \mathrm{C}$. (c) XRD patterns of the surface-modified titania monoliths calcined at different temperatures. 

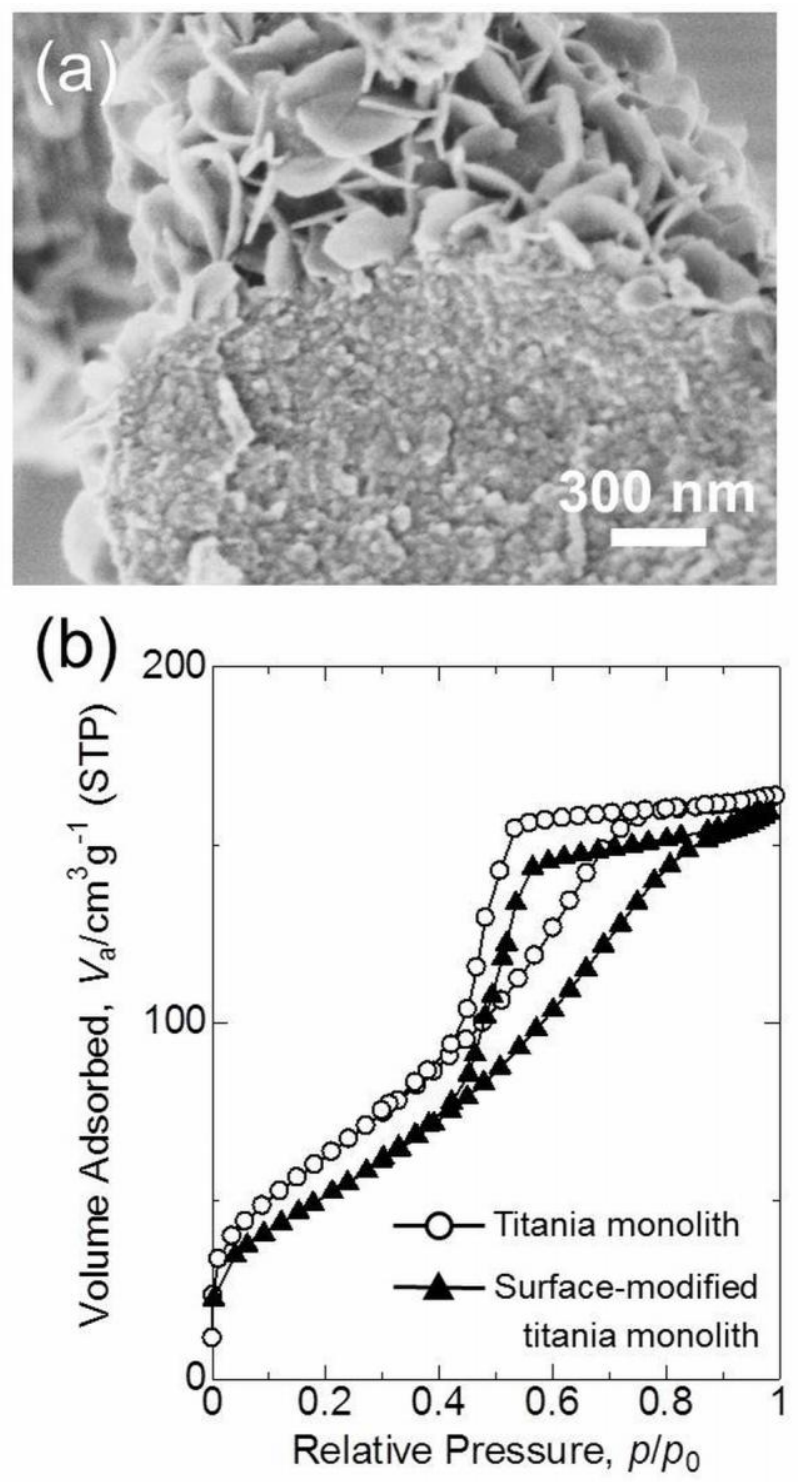

Figure 3 (a) FE-SEM image of the cross section of the skeleton in the surface-modified titania monolith. (b) Nitrogen adsorption-desorption isotherms of the titania monoliths with and without the surface modification. 
Table 1 Pore characteristics of the titania monoliths with and without the surface modification.

$$
V_{\mathrm{p}}{ }^{a} / \mathrm{cm}^{3} \mathrm{~g}^{-1} \quad S_{\mathrm{BET}}{ }^{b} / \mathrm{m}^{2} \mathrm{~g}^{-1} \quad D_{\mathrm{p}}{ }^{a} / \mathrm{nm}
$$

$$
\text { Titania monolith }
$$

Surface-modified titania monolith

$$
0.253
$$

0.246
220

190

\section{5}

5.5

\footnotetext{
${ }^{a}$ Total pore volumes $V_{\mathrm{P}}$ and mean pore diameter $D_{\mathrm{p}}$ obtained by the $\mathrm{BJH}$ method using adsorption branch. ${ }^{b}$ Specific surface areas calculated by BET method.
}

\subsection{Material characterization}

Characterizations of the platy materials were performed utilizing the particle samples prepared from the titania particles $(\sim 1 \mu \mathrm{m})$. Figure 4 shows the FE-SEM and TEM images of the particle samples after the treatment in $0.8 \mathrm{~mol} \mathrm{~L}^{-1} \mathrm{LiOH}$ aq. at $80{ }^{\circ} \mathrm{C}$ for $24 \mathrm{~h}$. Starting from titania particles, the aggregates of platy crystallites were obtained. The thickness of each plate is about $30 \mathrm{~nm}$. Unfortunately, it was found that TEM and electron diffraction are not available for the determination of crystal structure of the dried sample because the crystal phase changed during the observation due to the low thermal stability. The XRD patterns of the dried samples and samples calcined at different temperatures are shown in Figure 5 a. Comparing the XRD patterns of the as-dried sample prepared from titania monolith and titania particles, the platy materials on the surface of the titania monoliths are the same with those on the particles. All peaks except for the small peak of anatase (101) are attributed to LHLT [35,36]. The diffraction peak at $2 \theta \sim 10.5^{\circ}$ derives from the interlayer spacing of titanate $[29,37]$. The TG analysis result (Figure $5 \mathrm{~b}$ ) also indicates that the flower-like crystals include some crystal water, which causes the thermal 
instability of LHLT. The Raman spectrum of the as-dried powder shows four characteristic bands centered at 278, 435, 689, and $858 \mathrm{~cm}^{-1}$ as shown in Figure $5 \mathrm{c}$. The bands in the $250-400 \mathrm{~cm}^{-1}$ region and $400-700 \mathrm{~cm}^{-1}$ region correspond to the $\mathrm{Li}-\mathrm{O}$ stretches of $\mathrm{LiO}_{6}$ octahedra and $\mathrm{LiO}_{4}$ tetrahedra, respectively $[38,39]$. The bands in the $550-700 \mathrm{~cm}^{-1}$ region are assigined to Ti-O stretches in $\mathrm{TiO}_{6}$ octahedra $[38,39]$. The Raman scattering result indicates that the lithium ions occupy both octahedral and tetrahedral positions. The XRD patterns also show that the calcination at $200{ }^{\circ} \mathrm{C}$ changes the crystallites into $\mathrm{LiTiO}_{2}$ and the unidentified phase because of the loss of crystal water as shown in the TG result. The main crystal phase transforms into the spinel $\mathrm{Li}_{4} \mathrm{Ti}_{5} \mathrm{O}_{12}$ [36], which is known as the anode material for Li-ion battery [33,36], after the calcination above $300^{\circ} \mathrm{C}$.
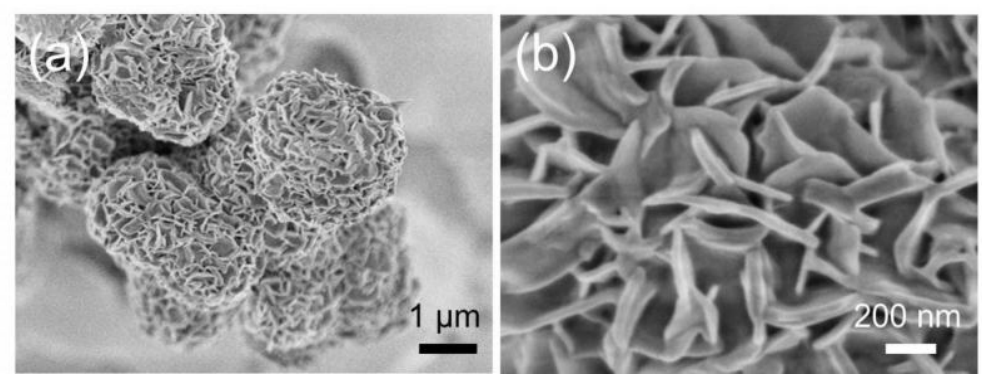

(c)

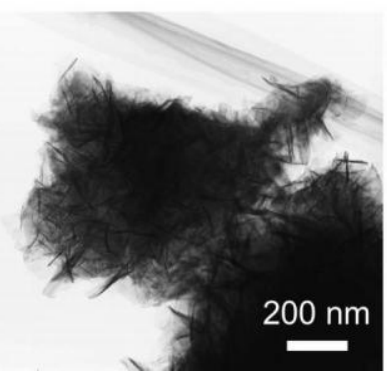

Figure 4 FE-SEM images (a,b) and TEM bright field image (c) of the dried sample prepared from the titania particles. 

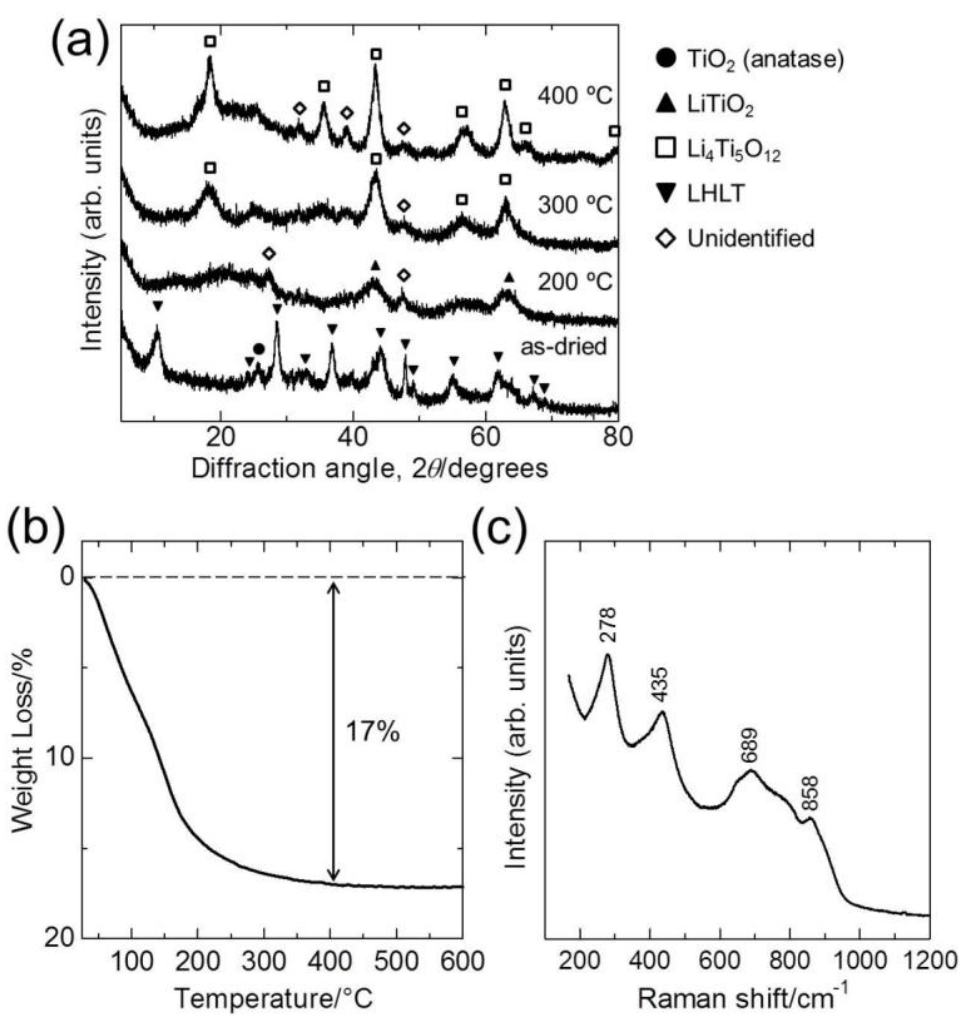

Figure 5 (a) XRD patterns of the dried and calcined particle samples. (b) TG analysis result of the dried sample prepared from the titania particles. (c) Raman spectrum of the dried sample prepared from the titania particles.

\subsection{Proposed mechanism}

The suggested formation mechanism of the crystallites is based on dissolution and re-precipitation. Many theoretical and electrochemical studies inform that Li ions can be easily intercalated due to the small ion size [40-42]. Therefore, Li ions would penetrate into the anatase crystallites from the surface. Then, the intercalated Li ions expand the Ti-O lattice 
to some extent [40,41], which enhances the solubility of titania. The dissolved species re-prepicitate with the surrounding $\mathrm{Li}$ ions as well as $\mathrm{H}_{2} \mathrm{O}$ resulting in the formation of layered hydrous lithium titanate crystallites on the surface of the titania material. When the treatment condition is weak, the dissolution does not occur, resulting in no change on the titania surface. On the other hand, when the treatment condition is strong, the anatase phase is directly transformed into $\mathrm{LiTiO}_{2}$ without forming platy crystallites.

\subsection{Effect of titania crystallinity on surface modification}

The surface modification process was also tried using the dried and the calcined titania monoliths instead of the wet gels as shown in Figure 6. The precursor titania monolith calcined at $700{ }^{\circ} \mathrm{C}$ was composed of rutile and the others were composed of anatase as shown in Figure S6. It is found that the surface modification of flower-like structure was achieved even with the titania monolith calcined at $500{ }^{\circ} \mathrm{C}$. On the other hand, there are only a few platy materials observed when starting from the sample calcined at $600{ }^{\circ} \mathrm{C}$ and there is no platy ones in the case of the rutile monolith. Comparing the titania monoliths calcined at $500{ }^{\circ} \mathrm{C}$ and 600 ${ }^{\circ} \mathrm{C}$, the difference is deduced to derive from the anatase crystallite size and the crystallinity of anatase in the precursors. The crystallite size of the titania monoliths calcined at $500{ }^{\circ} \mathrm{C}$ and $600{ }^{\circ} \mathrm{C}$ are calculated as $c a .10 \mathrm{~nm}$ and $c a .30 \mathrm{~nm}$ by Scherrer's equation. The crystallinity of the titania monoliths calcined at higher temperature is higher. The larger crystallites with 
higher crystallinity lead to the slower intercalation of Li ions [42] and less solubility, which supresses the formation of platy crystallites. In the case of the rutile monolith, the intercalation of $\mathrm{Li}$ ions into rutile takes place slower than that into anatase [40]. Hence, the surface modification is not effective for the rutile material. It is also observed that the size of the platy objects changed depending on the precursors. Starting from the dried and calcined samples, the sizes of each plate are obviously larger compared to the case of the sample prepared using the wet titania gel. This fact can be explained by the roughness of the surface of the precursor. The surface of the dried monolith is smoother than that of the wet gel due to the densification during drying caused by the surface tension. The smoother surface leads to the less nucleation cites, which indicates that less crystal nuclei are formed in the initial period of re-precipitation. Each crystallite therefore grows up better resulting in the larger platy crystallites in the case of the dried and calcined titania monoliths.

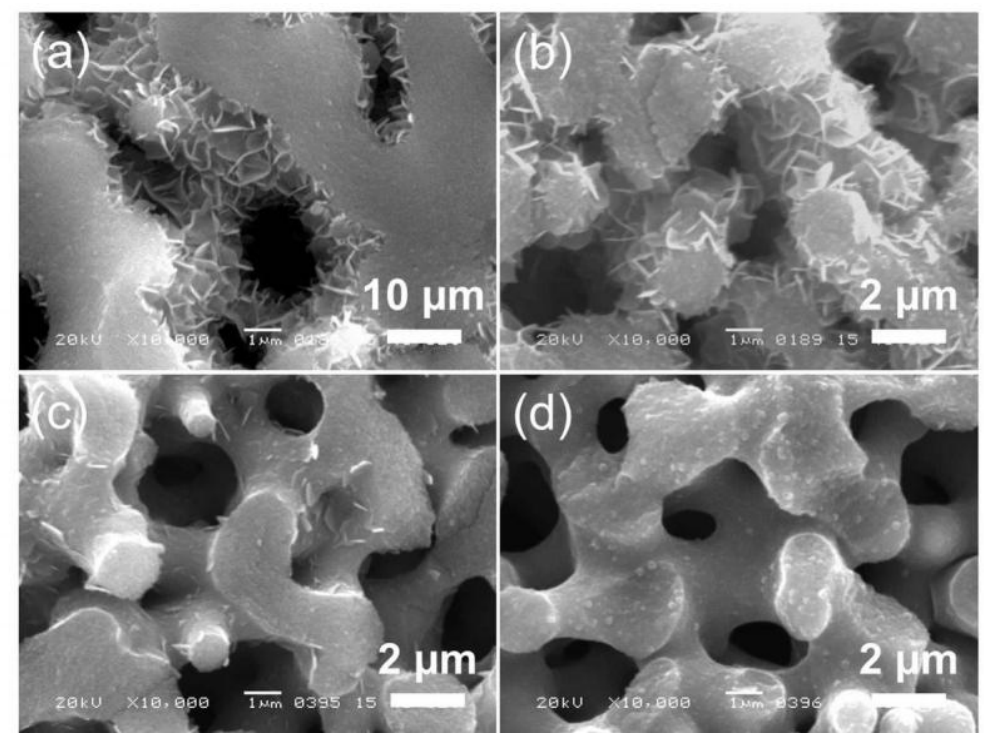


Figure 6 SEM images of the surface-modified titania monoliths prepared from (a) the dried titania and the titania monoliths calcined at (b) $500{ }^{\circ} \mathrm{C}$, (c) $600{ }^{\circ} \mathrm{C}$, and (d) $700{ }^{\circ} \mathrm{C}$.

\section{Conclusions}

We have found a unique reaction can occur on the surface of titania materials in lithium hydroxide aqueous solution, which can be applied to the surface modification of titania materials. Under weak treatment conditions, no change in structure or crystal phase occurs on titania materials. On the other hand, when the treatment conditions are relatively strong, transformation into $\mathrm{LiTiO}_{2}$ with no structural change is observed [32,33]. These flower-like structures form on the surface of titania materials under intermediate conditions. This structure retains after calcination at up to 700 ${ }^{\circ} \mathrm{C}$ whereas the crystal phase transforms into $\mathrm{Li}_{4} \mathrm{Ti}_{5} \mathrm{O}_{12}$. The as-dried platy materials which form the flower-like structures have been identified as layered hydrous lithium titanate $[35,36]$. The formation of the flower-like structures is based on dissolution and re-precipitation. It is deduced that the high intercalation properties of small Li ions cause the dissolution of titania under mild conditions. When the titania materials are composed of large anatase or rutile with high crystallinity, the structural change was not observed due to the poor dissolution of titania.

\section{Acknowledgement}

The present work was supported by the Grant-in-Aid for Scientific Research (No. 22.75 for G.H. 
and No. 20750177 for K.K.) from the Ministry of Education, Culture, Sports, Science and Technology (MEXT), Japan. Also acknowledged is the Global COE Program "International Center for Integrated Research and Advanced Education in Materials Science" (No. B-09) of the MEXT, Japan, administrated by the Japan Society for the Promotion of Science (JSPS).

\section{References}

[1] A. Fujishima, K. Honda, Nature 238 (1972) 37.

[2] H. Tang, K. Prasad, R. Sanjinés, P.E. Schmid, F. Lévy J. Appl. Phys. 75 (1994) 2042.

[3] A. L. Linsebigler, G. Lu, J. T. Yates, Jr., Chem. Rev. 95 (1995) 735.

[4] S.-D. Mo, W.Y. Ching, Phys. Rev. B 51 (1995) 13023.

[5] R. Marchand, L. Brohan, M. Tournoux, Mat. Res. Bull. 15 (1980) 1129.

[6] M. Grätzel, Nature 414 (2001) 338.

[7] N.-G. Park, J. van de Lagemaat, A.J. Grank, J. Phys. Chem. B 104 (2000) 8989.

[8] M.R. Hoffmann, S.T. Martin, W. Choi, W. Bahnemann, Chem. Rev. 95 (1995) 69.

[9] M.W.H. Pinkse, P.M. Uitto, M.J. Hilhorst, B. Ooms, A.J.R. Heck, Anal. Chem. 76 (2004) 3935.

[10] J. Konishi, K. Fujita, K. Nakanishi, K. Hirao, K. Morisato, S. Miyazaki, M. Ohira, J. Chromatogr. A 1216 (2009) 7375.

[11] Y. Zhou, M. Antonietti, J. Am. Chem. Soc. 125 (2003) 14960.

[12] Z. Zhong, Y. Yin, B. Gates, Y. Xia, Adv. Mater. 12 (2000) 206.

[13] D. Chen, L. Cao, F. Huang, P. Imperia, Y.-B. Cheng, R.A. Caruso, J. Am. Chem. Soc. 1322010 
4438.

[14] J.D. Bass, D. Grosso, C. Boissiere, C. Sanchez, J. Am. Chem. Soc. 130 (2008) 7882.

[15] H. Li, Z. Bian, J. Zhu, D. Zhang, G. Li, Y. Huo, H. Li, Y. Lu, J. Am. Chem. Soc. 129 (2007)

8406.

[16] Y.-G. Guo, Y.-S. Hu, W. Sigle, J. Maier, Adv. Mater. 19 (2007) 2087.

[17] G. Hasegawa, K. Kanamori, K. Nakanishi, T. Hanada, J. Am. Ceram. Soc. 93 (2010) 3110.

[18] G. Hasegawa, K. Kanamori, K. Nakanishi, T. Hanada, J. Sol-Gel Sci. Technol. 53 (2010) 59.

[19] G. Hasegawa, K. Morisato, K. Kanamori, K. Nakanishi, J. Sep. Sci. 34 (2011) 3004.

[20] J.R. Conrad, J.L. Radtke, R.A. Dodd, F.J. Worzala, N.C. Tran, J. Appl. Phys. 62 (1987) 4591.

[21] J.L. Figueiredo, M.F.R. Pereira, M.M.A. Freitas, J.J.M. Órfão, Carbon 37 (1999) 1379.

[22] H. Minakuchi, K. Nakanishi, N. Soga, N. Ishizuka, N. Tanaka, Anal. Chem. 68 (1996) 3498.

[23] X.S. Zhao, G.Q. Lu, J. Phys. Chem. B 102 (1998) 1556.

[24] K. Kato, E. Uchida, E.T. Kang, Y. Uyama, Y. Ikeda, Prog. Polym. Sci. 28 (2003) 209.

[25] N. Yamaguchi, K. Tadanaga, A. Matsuda, T. Minami, M. Tatsumisago, J. Sol-Gel. Sci. Technol. $33(2005) 117$.

[26] H. Zhang, J.F. Banfield, J. Mater. Chem. 8 (1998) 2073.

[27] J. Nawrocki, C. Dunlap, A. McCormick, P.W. Carr, J. Chromatogr. A 1028 (2004) 1.

[28] T. Kasuga, M. Hiramatsu, A. Hoson, T. Sekino, K. Niihara, Langmuir 14 (1998) 3160.

[29] A.R. Armstrong, G. Armstrong, J. Canales, P.G. Bruce, Angew. Chem. Int. Ed. 43 (2004) 2286.

[30] Y. Lan, X. Gao, H. Zhu, Z. Zheng, T. Yan, F. Wu, S.P. Ringer, D. Song, Adv. Funct. Mater. 15 
(2005) 1310.

[31] M. Tomiha, N. Masaki, S. Uchida, T. Sato, J. Mater. Sci. 37 (2002) 2341.

[32] L.M. Sikhwivhilu, S.S. Ray, N.J. Coville, Appl. Phys. A 94 (2009) 963.

[33] C. Jiang, E. Hosono, M. Ichihara, I. Honma, H. Zhou, J. Electrochem. Soc. 155 (2008) A553.

[34] T. Onda, S. Shibuichi, N. Satoh, K. Tsujii, Langmuir 12 (1996) 2125.

[35] M. Sugita, M. Tsuji, M. Abe, Bull. Chem. Soc. Jpn. 63 (1990) 1978.

[36] Y. Tang, L. Yang, S. Fang, Z. Qiu, Electrochim. Acta 54 (2009) 6244.

[37] R. Yoshida, Y. Suzuki, S. Yoshikawa, J. Solid State Chem. 178 (2005) 2179.

[38] T. Nakazawa, V. Grismanovs, D. Yamaki, Y. Katano, T. Aruga, Nucl. Instrum. Methods Phys.

Res. B 206 (2003) 166.

[39] L. Aldon, P. Kubiak, M. Womes, J.C. Jumas, J. Olivier-Fourcade, J.L. Tirado, J.I. Corredor, C.P.

Vicente, Chem. Mater. 16 (2004) 5721.

[40] A. Stashans, S. Lunell, R. Bergström, A. Hagfeldt, S.-E. Lindquist, Phys. Rev. B 53 (1996) 159.

[41] R. van de Krol, A. Goossens, J. Schoonman, J. Phys. Chem. B 103 (1999) 7151.

[42] M. Wagemaker, W.J.H. Borghols, F.M. Mulder, J. Am. Chem. Soc. 129 (2007) 4323. 
Supporting Information

Flower-like Surface Modification of Titania Materials

by Lithium Hydroxide Solution

By George Hasegawa,* Kazuyoshi Kanamori, Yoshihiro Sugawara, Yuichi Ikuhara, and Kazuki

Nakanishi
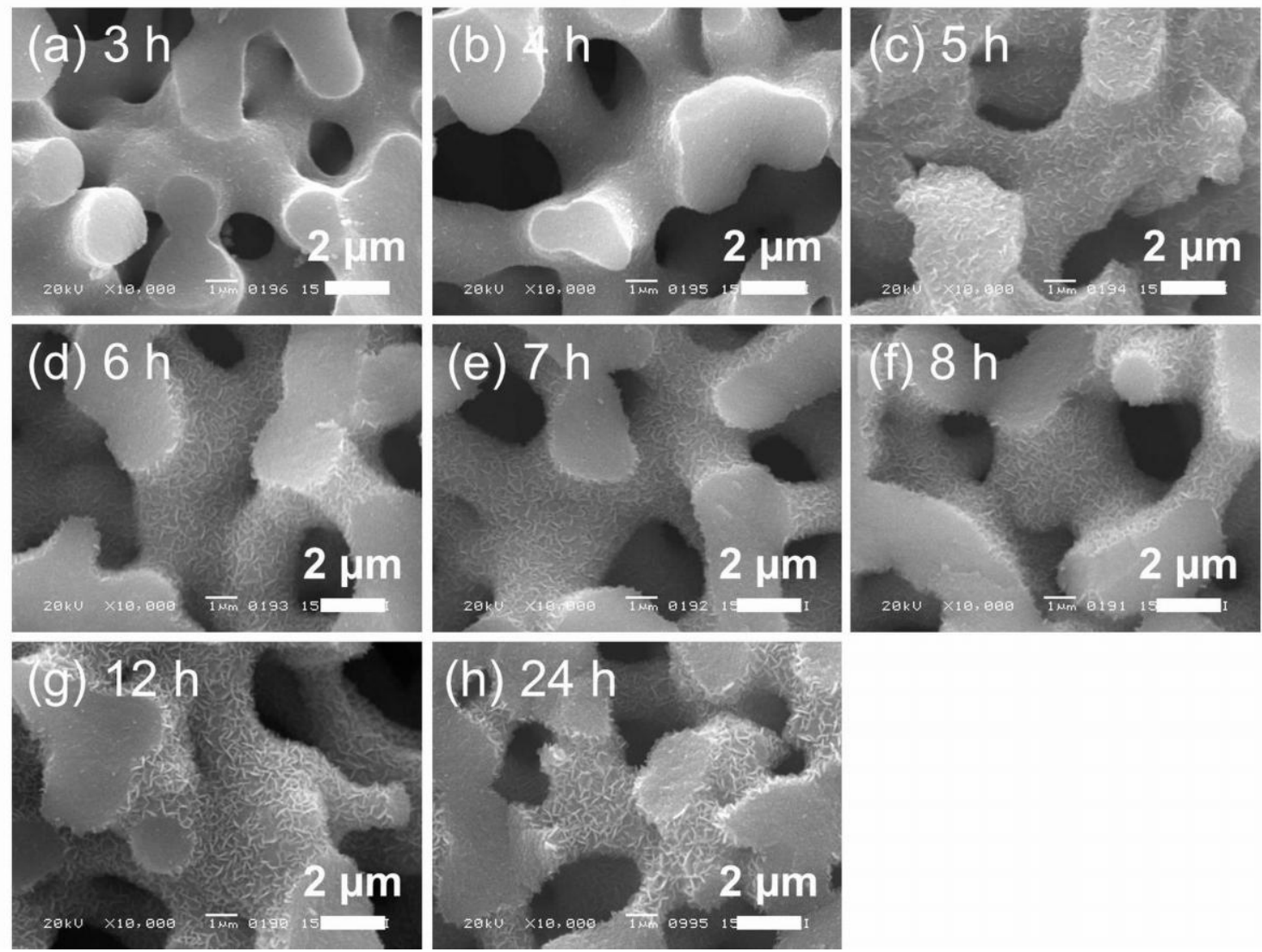

Figure S1 SEM images of the titania monoliths after the treatment in $0.8 \mathrm{~mol} \mathrm{~L}-1 \mathrm{LiOH}$ aq. at 80 ${ }^{\circ} \mathrm{C}$ for different durations. 

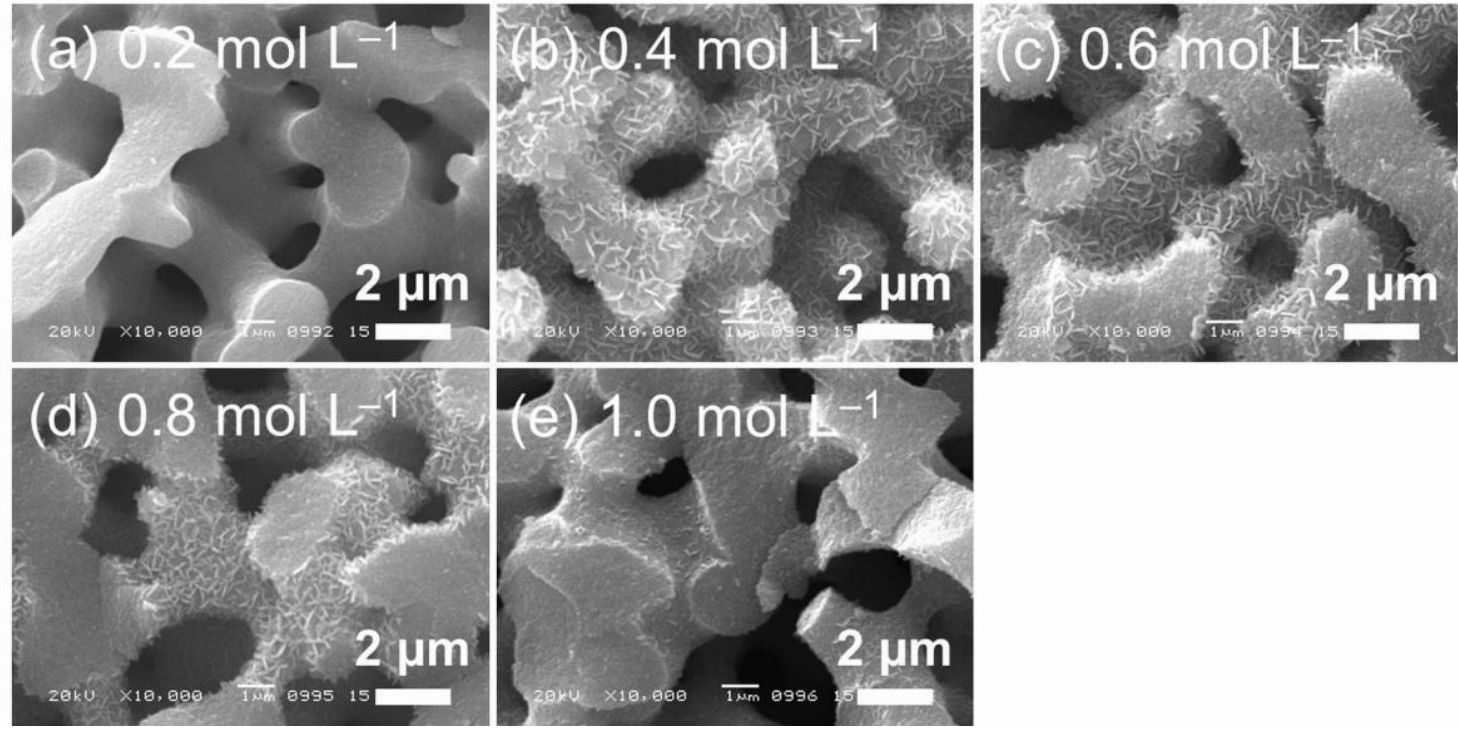

Figure S2 SEM images of the titania monoliths after the treatment in different concentrations of LiOH aq. at $80^{\circ} \mathrm{C}$ for $24 \mathrm{~h}$.
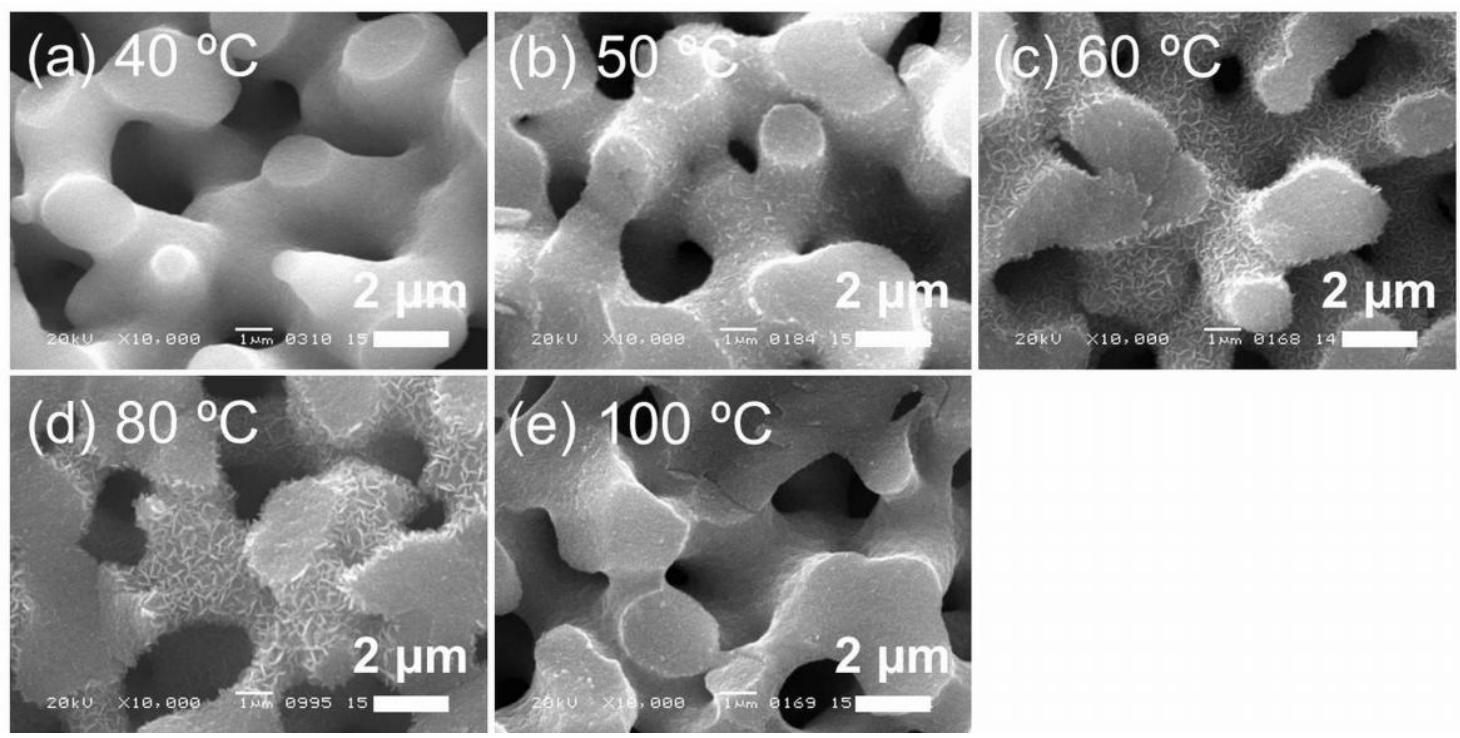

Figure S3 SEM images of the titania monoliths after the treatment in $0.8 \mathrm{~mol} \mathrm{~L}-1 \mathrm{LiOH}$ aq. at different temperatures for $24 \mathrm{~h}$. 

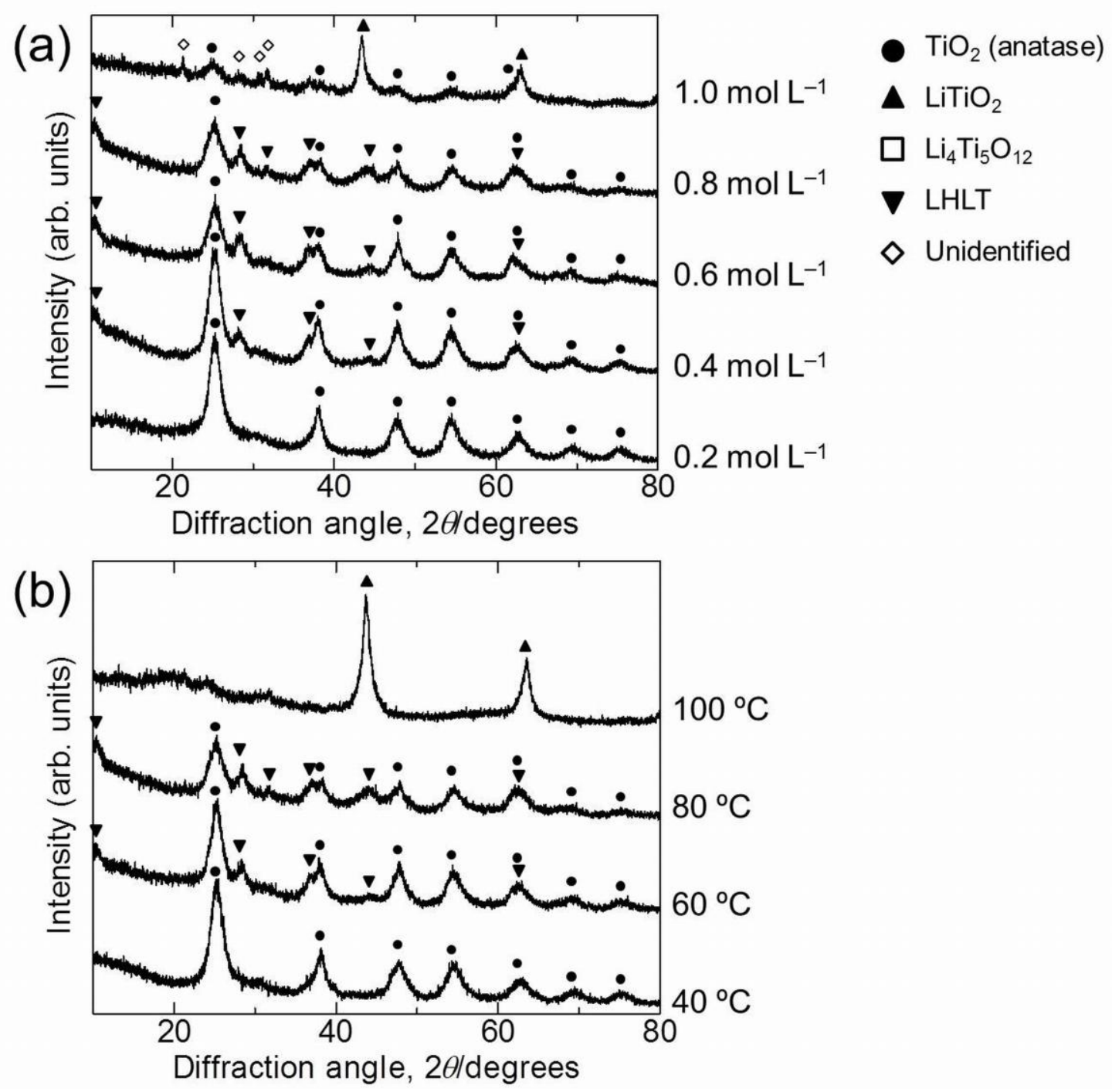

Figure S4 XRD patterns of the titania monoliths treated in various conditions; (a) treated in various concentrations of $\mathrm{LiOH}$ aq. at $80{ }^{\circ} \mathrm{C}$ for $24 \mathrm{~h}$ and (b) treated in $0.8 \mathrm{~mol} \mathrm{~L}-1 \mathrm{LiOH}$ aq. at various temperatures for $24 \mathrm{~h}$. 


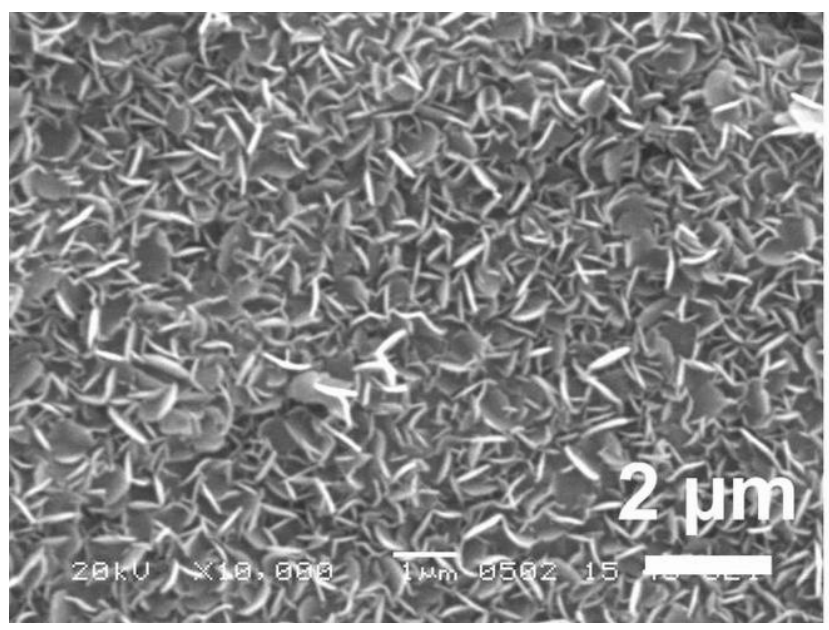

Figure S5 SEM image of the flower-like structure on the flat titania surface.

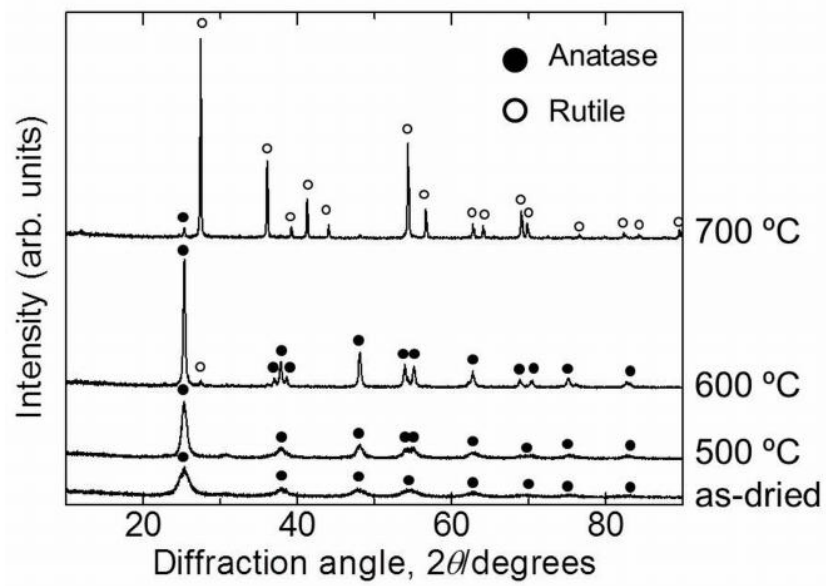

Figure S6 XRD patterns of the precursor titania monoliths which has been dried and calcined. 